\title{
Mental Health Concern During COVID-19 Pandemic in Nepal
}

Anisha Chalise ${ }^{1}$, Shishir Paudel ${ }^{2}$

\section{Author Info:}

${ }^{1}$ Central Department of Public Health, Institute of Medicine, Tribhuvan University, Kathmandu, Nepal

\section{${ }^{2}$ Manmohan Memorial} Institute of Health Sciences, Kathmandu, Nepal

Email: shishirpaudel11@gmail. com ORCID: 0000-0003-30776697

\section{Corresponding Author:}

Anisha Chalise;

Email/Orcid ID:

anisha.chalise90@gmail.com ORCID: 0000-0003-1478-454X

\section{ABSTRACT}

The whole world struggles to combat COVID-19 pandemic forcing nations to take extreme measures in an attempt to prevent outbreaks and save lives. It has been noted that COVID-19 has established itself as a risk factor for psychological distress among the population of different subgroups. There are several factors such as uncertainties, controversies, misinformation, social isolation, stigma and discrimination which are escalating the risk of massive mental distress among the public. Nepal is trying to increase its effort to combat COVID-19 by adopting community containment measures, but the mental health of the frontline health workforce, service providers and the general public seems to be highly overshadowed. In this aspect, this paper aims to shed light over different aspects of mental health issues emerging in Nepal during the time of COVID-19 lockdown, along with some of its potential contributing factors. Nepal lacks adequate infrastructure and human resource to provide mental healthcare services effectively in case of any massive mental distress. In this state of resource deprivation, providing education and training regarding psychosocial issues to health system leaders, first responders and health care professionals could be a key to address the population need at present and to prevent further complications.

Keywords: COVID-19; Mental health; Novel coronavirus 2019; Psychological distress; SARS-CoV-2

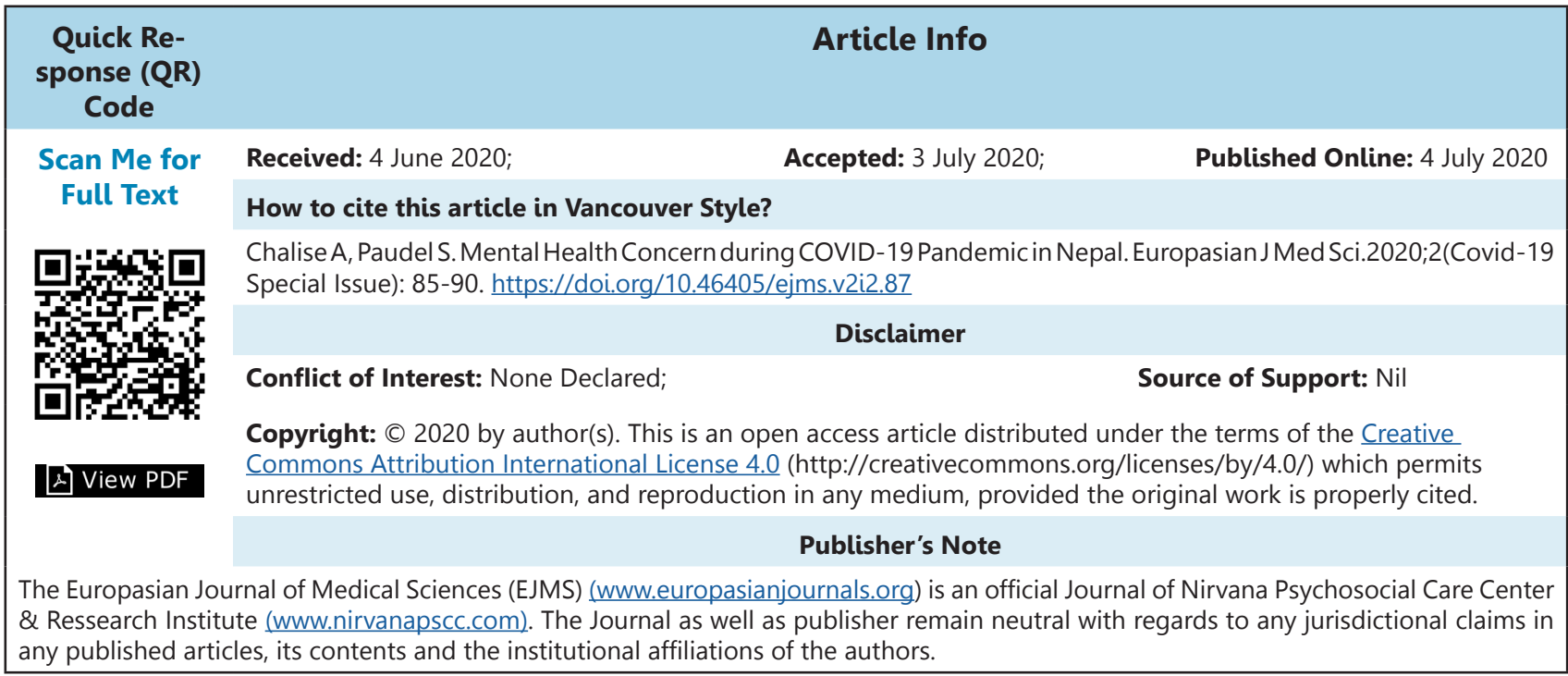




\section{INTRODUCTION}

The 2019 coronavirus disease (COVID-19), which emerged as an unknown outbreak of pneumonia in Wuhan on December 2, 2019 spread rapidly throughout the world forcing it to be recorded as a global pandemic on March 11, 2020 after infecting 118,319 global citizens and claiming 4,292 deaths..$^{1-3}$ By July 3, 2020, COVID-19 accounted for $10,710,005$ confirmed cases of infection and 517,877 deaths around 200 countries. $^{1}$ COVID-19 has been resulting in many psychological problems such as anxiety, depression, insomnia and stress among medical personnel, as well as among the general public due to several factors such as uncertainties, high rate of infection, controversies, misinformation and an increasing number of cases and deaths globally. ${ }^{4-7}$

Nepal experienced its first case of COVID-19 on January 25, 2020 in a Nepalese male student who had returned from the Wuhan City of China. He recovered within a week and was tested negative on Reverse transcription polymerase chain reaction (RT-PCR) confirmation. ${ }^{8}$ The second case was reported only after a month on March 23, 2020 and until April 4, 2020 all the reported cases in Nepal were imported cases. ${ }^{9-11}$ On April 4, 2020 the country reached to the second stage of infection after a woman from Kailali district with no prior history of travel was found to be infected. ${ }^{9}$ There is a small proportion of locally transmitted infections while most of the confirmed cases have been imported from India. The COVID-19 cases in Nepal is in rapid raise and as of July 3,2020, there has been 14,519 confirmed cases of COVID-19, of which 6,143 had recovered and 31 deaths have been recorded. Despite having limited resources, Nepal is trying to increase its effort to combat COVID-19 by adopting community containment measures, international travel restrictions, border closure, and country-wide lockdown along with an increase in healthcare facilities testing sites and coverage. 9,12 But still, in this struggle against this SARS-CoV-2 virus, the mental health of the frontline health workforce, service providers and the general public seems to be highly overshadowed. No original research study concerning the mental health status of the general public or medical providers during this state of pandemic has been published to date in the Nepalese context. However, on 18 May 2020, Nepal Health Research Council (NHRC) published the list of nineteen COVID-19 related research proposals that were approved by the ethical review board of which eleven studies were concerned with the mental health among different population subgroups. ${ }^{13}$

\section{Effects of COVID-19 on Mental Health}

The effect of current COVID-19 pandemic over the global mental health has not been registered and measured sufficiently. There have been limited studies concerning this issue, however, some references can be drawn from the past epidemic of similar infections such as of SARS-CoV outbreak of 2003 and MARS-CoV of 2015. There are many factors which make the healthcare providers vulnerable to mental distress such as high risk of contacting the infection, heavy workload, inadequate protection against contamination, frustration and poor social support as well as feeling of isolation from the general public., 5,14 A recent survey conducted among 1257 healthcare workers in China during the first week of February 2020 found that more than half of the healthcare providers had experienced the symptoms of depression, anxiety, insomnia, and distress. ${ }^{7}$ The general population is also at the high risk of mental distress. Likewise, An online survey performed among 4872 participants from 31 provinces of China during the first week of February 2020 found that almost half, i.e. $48.3 \%(95 \% \mathrm{Cl}$ : 46.9\%-49.7\%) of the participants had experienced depression and $22.6 \%$ (95\% Cl: $21.4 \%-23.8 \%$ ) of the participants had a certain level of anxiety, which were positively associated with frequent exposure to social media during the COVID-19.15 Similarly, A nationwide survey of China found that almost one-third of the general public have experienced certain psychological distress due to COVID-19. ${ }^{16}$

\section{Status of Nepal during COVID-19 Lockdown}

A media survey was conducted during the time of lockdown between April 23 and May 3 by Transcultural Psychosocial Organization (TPO) to study the social impact of COVID-19. The study consisted of 2,014 participants residing in Nepal. It was observed that almost 50 percent of the participants reported having at least one psychosocial problem, whereas, 32 percent reported having two or more psychosocial problems ranging from restlessness, fearfulness, anxiety, worry and sadness. ${ }^{17}$ It has been noted that people are consuming alcohol as a coping mechanism, which has further added to the existing mental and physiological distress. ${ }^{17}$ This has led to numerous death accounted for alcohol poisoning and the cases of domestic violence and abuse. The Women's Rehabilitation Center (WOREC) a national organization of Nepal recorded that, during the time of lockdown form 24 March 2020 to 9 May 2020, there have been 231 reported cases of 


\section{Reported Cases of Voilence against Women during Lockdown}

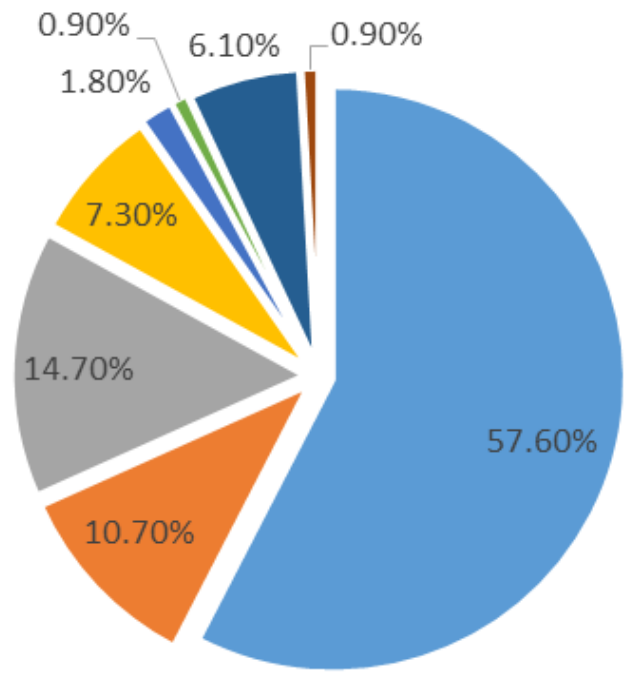

Figure 1: Reported cases GBV against women and girls during lockdown form 24 March to 9 May $2020 . .^{18}$

The World Health Organization (WHO) 2016 estimates that the crude suicide rate for Nepal stands at 8.8 suicides per 100,000 populations. ${ }^{19}$ At the time of lockdown from 24 March to Jun 6, 2020 , in 74 days of lockdown it has been estimated that the suicidal rate has been increased by 20 percent as 1,200 cases of suicide throughout the country has been reported. This illustrates almost 17 lives have been lost per day due to suicide during the period of lockdown..$^{20}$ This is of public health concern as it has been highly acknowledged that the suicidal rates might rise higher during the time of public health emergencies. ${ }^{20,21}$ There are multiple risk factors such as economic stress, social isolation, poor access to mental health services and barriers to treatments, rising fear of death, loss of someone significant, work stress, social stigma and discrimination which could influence the rate of suicidal tendency during the COVID-19 crisis. ${ }^{20,21}$

In Nepal, the majority of the mental health facilities are concentrated in urban areas. The mental health policy framework has not been implemented properly and deficient budget allocation limits the provision of infrastructure and human resources for effective mental health service provision. ${ }^{22}$ WHO-AIMS report on the mental health system in Nepal of 2006 estimates there are only 0.129 psychiatrists and 0.024 psychologists available per 100,000 populations in Nepal. However, it has been noted that a considerable proportion of the general
- Domestic Violence

- Social Violence and Cyber Crime

- Rape

- Sexual abuse and Attempt to Rape

- Attempt to Muder or Suicide

- Muder

- Suicide

- Muder or Sucide (Unidentified Cases)

population exhibit a certain level of depressive symptoms and mental distress. ${ }^{23-26}$ At the time of the 2015 earthquake, it was estimated that onethird of Nepalese suffered from some form of psychiatric disorder resulted due to the years of civil unrest and the devastating earthquake. ${ }^{27}$ Due to these variations in the supply and demand for mental health services, Nepal struggles to provide specialist care even at normal circumstances. Thus it is a challenge for the country to expand its services during the time of pandemic or any other disaster. To bridge these gaps, the basic mental health counseling and referral mechanism can be adopted at the healthcare units and community level so that the mental distress among the population could be addressed before it leads to massive mental health consequences.

\section{Factors contributing to Mental distress}

Different countries are adopting different strategies to combat the COVID-19 pandemic. In the absence of effective medicine and vaccines, the only effective strategies that have been noted to prevent the outbreak is to reduce the mixing of susceptible people with a healthy community. ${ }^{11}$ This has forced the countries to adopt extraordinary public health measures that involve traditional strategies of isolation, quarantine, social distancing and community containment. ${ }^{12,28,29}$ Either if it is complete lockdown or any measures of socialdistancing or physical distancing, people are being forced to change their social practices and contain themselves within certain boundaries. The WHO acknowledges the fact that these restrictions could 
certainly bring a massive mental health impact on the global population. It has been advised by the WHO that the public fears and anxiety should not be ignored and that the individuals, community and the government should act to address these issues. ${ }^{30}$ However, the mental health of the people has been shadowed in the present context where the nations struggle to control infection and symptomatic treatment of patients to save lives.

The economic and social isolation cost is estimated to be high for Nepal. The country's economy is highly dependent on the remittance received from Nepalese foreign employment and national tourism, both of which are highly affected by COVID-19 and in total 8 to 10 percent of GDP is expected to be affected. ${ }^{31}$ This has resulted in a fear of long-term economic hardship to the Nepalese citizens. The lockdown has resulted in job losses and business failures which has impacted every Nepalese citizen but mostly to those families who rely on a daily income for livelihood. Moreover, thousands of Nepalese citizens who went for foreign employment are trapped abroad unable to return home. The reported COVID-19 death among Nepalese citizens residing abroad has been rising as of June 14 2020, 17,792 Non-resident Nepalese (NRNs) were reported to be infected of which 127 died. ${ }^{32}$ This has not just added to the pain of losing a member of a family but has fueled the fear of losing someone without ever seeing them.

It is not just the working group that has been affected, the elderly population are also dealing with constant fear of infection and death as the media constantly reports higher risk among the elderly population and people with chronic conditions. It has also been foreseen that the closing of the schools for a long time could amplify the mental health impact in children, putting them at risk of losing the sense of structure and stimulation which is provided by the school environment. ${ }^{30,33}$ The students of higher education are concerned with their academic courses, exams and career as the country struggles to resume the academic session and change its modality of traditional education system. The children and the youths are getting addicted to online gaming and the internet. In addition, the children are not being able to receive the opportunity to be with their friends and get the social support which is essential for good mental well-being. ${ }^{30}$

The rapid increase in the rate of infection along with the increased exposure to distressing news, uncertainty, misleading information and increased stressors during the COVID19 lockdown are stimulating numerous mental health issues. At the time of this pandemic, the patient under quarantine have to face the fear of death, loneliness, rape and violence and poor social support which increases the likelihood of frustration, insomnia, anxiety and distress. ${ }^{4,21}$ Furthermore, the rising confusion and crisis resulted due to COVID-19 outbreak certainly has provoked social stigma and discriminatory behaviors against people of certain ethnic backgrounds, suspected people as well as healthcare service providers. ${ }^{4,34}$ At this hard times, the healthcare providers and frontline workers are forced to work extra hours, in a tensed environment without adequate protection which keeps them at a high risk of infection. They are risking their life and living in voluntary isolation to serve the people, meanwhile, being deprived form their allowances, not receiving proper facilities, having poor support and are being subjected to social discrimination and even in some place even being forced to evacuate their homes. ${ }^{35,36}$ All of this has negatively impacted the social and mental wellbeing of the individuals. This has raised several social issues which can be seen in the form of violation of lockdown strategies, disapproval by people to live in quarantine facilities, as well as youth-led protests against government strategies to tackle COVID-19. ${ }^{37}$

\section{Strategies in response to Mental distress}

The National Health Commission of China notified an issue of guiding principles of emergency psychological crisis intervention for COVID-19. ${ }^{4}$ 38 Based on the learning from the mental health issues and interventions adopted during SARS outbreak of 2003, this notification called for the provision of mental healthcare to be provided for COVID-19 patients, close contacts, suspected cases, patients in fever clinics, families and friends of affected people, health professionals caring for infected patients and the public who are in need. ${ }^{4}$ Furthermore, to address the issue of mental distress experienced by the medical professional during the treatment of COVID-19 patients, the local government of Wuhan established a shift system to allow front-line medical workers to rest and to take turns in high-pressured roles. In addition, the psychological intervention team was established which was responsible to formulate intervention materials, provided technical guidance, supervise and provide psychiatric assistant to the health care providers and patients. ${ }^{5}$

The World Health Organization, has provided a 
recommendation document as "Mental health and psychosocial considerations during the COVID-19 outbreak" addressing different population groups to address the mental health issues. ${ }^{39}$ This document aims to communicate different recommendations targeting general population, children, care takers, people living in isolation, health facilities and healthcare workers to support their meantal and psychosocial well-being. Furthermore, a fact sheets provided by the WHO on Mental Health in Emergency, suggest that, for effective emergency response the basic clinical mental health services can be provided at every health-care facility by a trained and supervised general health staff to address population needs. ${ }^{40}$ At the time of disaster or health emergency there is a need to establish mental health and emergency management committee that can bear the responsibility of identifying, developing and disseminating evidence-based resources and intervention in regard to mental health. Links and referral mechanism can be established between mental health specialists, general health-care providers and community-based organizations to strengthen the response. ${ }^{40}$

\section{CONCLUSION}

In summary, the COVID-19 pandemic has caused tremendous psychological problems in different subpopulations and there is an urgent need to focus on the strategies to prevent massive mental health impacts on the public. As there are limited resources available in mental healthcare, providing education and training regarding psychosocial issues to health system leaders, first responders and health care professionals could be a key to address the population need at present. Furthermore, there is a need to develop a mental health and emergency management committee with a responsibility to identify, develop and disseminate evidence-based resources and intervention in regard to mental health during the time of disaster and epidemics in a developing nation such as Nepal.

\section{REFERENCES}

1. World Health Organization (WHO). Coronavirus disease (COVID-2019) situation reports 2020. Accessed 4 July 2020. [Link]

2. National Health Commission of the Pople's Republic of China. Timeline of China releasing information on COVID-19 and advancing international cooperation; 2020. Accessed18 April 2020. [Link]

3. World Health Organization (WHO). WHO announces
COVID-19 outbreak a pandemic 2020. Accessed 5 May 2020. [Link]

4. Xiang Y-T, Yang Y, Li W, Zhang L, Zhang Q, Cheung $T$, et al. Timely mental health care for the 2019 novel coronavirus outbreak is urgently needed. Lancet Psychiatry. 2020;7(3):228-9. doi: https://doi. org/10.1016/S2215-0366(20)30046-8 [Crossref] [PubMed]

5. Kang L, Li Y, Hu S, Chen M, Yang C, Yang BX, et al. The mental health of medical workers in Wuhan, China dealing with the 2019 novel coronavirus. Lancet Psychiatry. 2020;7(3):e14. doi: https://doi. org/10.1016/S2215-0366(20)30047-X [Crossref] [PubMed]

6. Bao Y, Sun Y, Meng S, Shi J, Lu L. 2019-nCoV epidemic: address mental health care to empower society. Lancet . 2020;395(10224):e37-e8. doi: https://doi. org/10.1016/S0140-6736(20)30309-3 [Crossref] [PubMed]

7. Lai J, Ma S, Wang Y, Cai Z, Hu J, Wei N, et al. Factors Associated With Mental Health Outcomes Among Health Care Workers Exposed to Coronavirus Disease 2019. JAMA network open. 2020;3(3):e203976. doi: $\quad$ https://doi.org/10.1001/jamanetworkopen. 2020.3976 [Crossref]

8. Bastola A, Sah R, Rodriguez-Morales AJ, Lal BK, Jha $\mathrm{R}$, Ojha HC, et al. The first 2019 novel coronavirus case in Nepal. Lancet Infect Dis. 2020;20(3):279-80. doi: https://doi.org/10.1016/S1473-3099(20)30067o [Crossref] [PubMed]

9. Ministry of Health and Population. Health Emergency Operation Center. Coronavirus disease (COVID-19) outbreak updates \& resource materials 2020. Accessed 4 July 2020. Link

10. Marahatta SB, Paudel S, Aryal N. COVID-19 Pandemic: What can Nepal do to Curb the Potential Public Health Disaster? Journal of Karnali Academy of Health Sciences. 2020;3(1):1-4. doi:https://doi. org/10.3126/jkahs.v3i1.28374 [Crossref Google Scholar]

11. Paudel $S$, Dangal G, Chalise A, Bhandari TR, Dangal $O$. The Coronavirus Pandemic: What Does the Evidence Show? J Nepal Health Res Counc. 2020;18(1):1-9. doi: https://doi.org/10.33314/jnhrc.v18i1.2596 [Crossref PubMed]

12. Pradhan TR. The Kathmandu Post: Government to close down border with India and China for a week. 2020. [Cited on 12 May 2020]. [Link]

13. Nepal Health Research Council (NHRC). COVID-19 related research proposals approved by NHRC. 2020. Assessed 27 June 2020. [Link]

14. Spoorthy MS. Mental health problems faced by healthcare workers due to the COVID-19 pandemic-A review. Asian J Psychiatr. 2020;51:102119. https://doi. org/10.1016/j.ajp.2020.102119 [Crossref PubMed]

15. Gao J, Zheng $P$, Jia $Y$, Chen $H$, Mao $Y$, Chen $S$, et al. Mental health problems and social media 
exposure during COVID-19 outbreak. PloS one. 2020;15(4):e0231924. doi: https://doi.org/10.1371/ journal.pone.0231924 [Crossref Google Scholar]

16. Qiu J, Shen B, Zhao M. A nationwide survey of psychological distress among Chinese people in the COVID-19 epidemic: implications and policy recommendations. Gen Psychiatr. 2020;33(2):e100213. doi: https://doi.org/10.1136/ gpsych-2020-100213 [PubMed Google Scholar]

17. Transcultural Psychosocial Organization Nepal (TPO). Lockdown casts a long shadow on people's mental health: Nationwide survey: Transcultural Psychosocial Organization; 2020 Accessed 13 May 2020. [Link]

18. Women's Rehabilitation Centre (WOREC). 231 Cases Of Violence Against Women And Girls Committed During Lockdown: Women's Rehabilitation Center; 2020 Accessed 13 May 2020. [Link]

19. World Health Organization (WHO). Global Health Observatory data repository. Suicide rate estimates, crude Estimates by country; 2016. Accessed 13 May 2020. [Link]

20. Paudel A. Over 1,200 people killed themselves during 74 days of lockdown. The Kathmandu Post. ekantipur.page 3. 2020. Accessed 27 June 2020. [Link]

21. Reger MA, Stanley IH, Joiner TE. Suicide Mortality and Coronavirus Disease 2019-A Perfect Storm? JAMA Psychiatry. 2020. doi: https://doi.org/10.1001/ jamapsychiatry.2020.1060 [Crossref PubMed]

22. Luitel NP, Jordans MJ, Adhikari A, Upadhaya $N$, Hanlon C, Lund C, et al. Mental health care in Nepal: current situation and challenges for development of a district mental health care plan. Confl Health. 2015;9:3. doi: https://doi.org/10.1186/s13031-0140030-5 [Crossref PubMed]

23. Khanal V, Mishra SR. Investment in mental health services urgently needed in Nepal. Lancet Psychiatry. 2016;3(8):707. doi:https://doi.org/10.1016/S22150366(16)30187-0 [Crossref PubMed]

24. Chalise A, Bhandari TR. Postpartum Depression and its Associated Factors: A Community-based Study in Nepal. J Nepal Health Res Coun. 2019;17(2):2005. doi: https://doi.org/10.33314/jnhrc.v0i0.1635 [Crossref PubMed]

25. Paudel S, Gautam H, Adhikari C, Yadav DK. Depression, Anxiety and Stress among the Undergraduate Students of Pokhara Metropolitan, Nepal. J Nepal Health Res Counc. 2020;18(1):27-34. doi: https://doi. org/10.33314/jnhrc.v18i1.2189 [Crossref PubMed]

26. Jha AK, Ojha SP, Dahal S, Sharma P, Pant SB, Labh S, et al. Prevalence of Mental Disorders in Nepal: Findings from the Pilot Study. J Nepal Health Res Coun. 2019;17(2):141-7. doi: https://doi.org/10.33314/ jnhrc.v0i0.1960 [PubMed Google Scholar]

27. Sherchan S, Samuel R, Marahatta K, Anwar N, Van Ommeren M, Ofrin R. Post-disaster mental health and psychosocial support: Experience from the 2015 Nepal earthquake. WHO South-East Asia J Public Health. 2017;6(1):22-9. doi: 10.4103/22243151.206160. [Crossref PubMed]

28. Wu Z, McGoogan JM. Characteristics of and Important Lessons From the Coronavirus Disease 2019 (COVID-19) Outbreak in China: Summary of a Report of 72314 Cases From the Chinese Center for Disease Control and Prevention. JAMA. 2020. doi: https://doi.org/10.1001/jama.2020.2648 Crossref Pubmed

29. Barron L. What We Can Learn From Singapore, Taiwan and Hong Kong About Handling Coronavirus. TIME 2020. Assessed on 13 May 2020. Link

30. World Health Organization (WHO). Regional office for Europe. Mental health and psychological resilience during the COVID-19 pandemic 2020. Accessed 13 May 2020. Link.

31. Koirala J, Acharya S. Economic Impact of COVID-19 in Nepal: A Question of Bad or Worst. SSRN. 2020. https://doi.org/10.2139/ssrn.3580840 Crossref Google Scholar

32. The Himialayan Times. No COVID-19 death of Nepalis abroad recored last week. 2020. Accessed 27 June 2020. Link

33. Marahatta SB, Paudel S. Tackling COVID-19 in Nepal: Opportunities and Challenges. Journal of Karnali Academy of Health Sciences. 2020;3. doi: https://doi. org/10.3126/jkahs.v3i1.28374 Crossref

34. World Health Organization (WHO). Coronavirus disease (COVID-19) technical guidance: Risk communication and community engagement 2020 . Accessed . Link.

35. Poudel A. Health workers deployed at COVID-19 fontline deprived of their allowances. The Kathmandu Post. 2020. Accessed 27 June 2020. Link

36. Poudel A, Aryal A. As COVID-19 fears grows, some medical personnel face eviction from their homes. The Kathmandu Post. 2020. Accessed 27 June 2020. Link

37. Dhungana S. Youth-led protests against the government's handling of COVID-19 spread to major cities. The Kathmandu Post. 2020. Accessed 27 June 2020. Link

38. Dong L, Bouey J. Public mental health crisis during COVID-19 pandemic, China. Emerg Infect Dis. 2020. Accessed 13 May 2020. doi: https://doi.org/10.3201/ eid2607.202407 Link

39. World Health Organization (WHO). Mental health and psychosocial considerations during the COVID-19 outbreak; 2020 Accessed 13 May 2020. Link

40. World Heath Organization (WHO). Mental Health in Emergencies. 2019. Assessed on 27 June 2020. Link 